\title{
Part A: Last Developments on Slag Valorization
}

\author{
Y. Pontikes • A. Malfliet
}

Published online: 1 April 2014

(C) Springer Science+Business Media Dordrecht 2014

The world is facing unprecedented environmental challenges and the transition to sustainable materials management, next to the transition towards a sustainable energy system, is now recognized as the path forward. Such a strategy will need to be based on resource efficiency, recovery and recycling and a multitude of synergetic and complementary actions are required from all actors. In this framework, the Third International Slag Valorization Symposium took place in 2013, aspiring to be one of the catalysts and contribute to this transition in the field of slags.

The symposium covered four thematic categories:

- Hot stage slag engineering for higher added value applications and energy recovery

- Metal recovery from slags and high temperature residues

- Critical metal recovery from slags and metallurgical residues

- High added value end-use of slags and metallurgical residues

In essence, these thematic categories cover the whole slag production and treatment chain, from the high temperature molten state and metal extraction, to solidification, metal recovery and end-products. This flow is also followed in our Special Issue "Slag Valorization Today".

The work by $\mathrm{Li}$ and Guo gives an overview on the current developments in the slag valorization domain in China. Considering that China is the largest iron- and steelmaking slag producer in the world and the intensive efforts made during the last decades, this report brings to light some of the undergoing pioneering work. The work of

Y. Pontikes $(\bowtie) \cdot$ A. Malfliet

KU Leuven, Kasteelpark Arenberg 44, 3001 Louvain, Belgium e-mail: Yiannis.Pontikes@mtm.kuleuven.be
Song et al., presents a novel process of vanadium extraction from vanadium-bearing slags already in its molten state with encouraging results. Staying still at the high temperature and new process development, Balomenos et al., presented a near zero-waste process for the conversion of metallurgical by-products into high added value products. Thermodynamic modelling and conceptual design for the processing of bauxite residues (red mud) from the primary aluminium industry and ferro-nickel production slags are presented as examples. In the case of bauxite residues, results of semi-industrial scale experiments are also presented, along with a preliminary financial analysis and an exergy flowsheet, all indicating that the proposed technology is financially viable and resourceefficient.

Moving to the solidification of slags, the work by Iacobescu et al. studies the stabilisation and microstructural modification of stainless steel converter slag. By utilising an industrial, alumina-rich by-product in a waste-synergy scheme, the authors managed to deliver a volumetrically stable slag.

Further use of slags in downstream applications has to meet a range of properties, depending on the application, but leaching is always a critical point. This however has not been the case historically and in the work of Cappuyns et al., legacy slags from the former $\mathrm{Pb}-\mathrm{Zn}$ mining industry are thoroughly characterised with special attention to heavy metal release and the relation of that to different management scenarios.

Considering the substantial volumes of metallurgical residues produced, it comes as no surprise that the building materials and construction sector receives great attention as a possible end-user. Slags for cement production, both as a raw material for clinker production and as a potential supplementary cementitious material, is one of the main 
paths explored. A notable example is blast-furnace slags, widely used as supplementary cementitious materials in blended cements because of their relatively high reactivity. This aspect of reactivity is investigated in the work of Snellings et al., after substituting $\mathrm{Ca}$ by $\mathrm{Mg}$ on synthetic glasses with similar composition to slags. By using a range of complementary experimental techniques and thermodynamic modelling, the authors show that reactivity is not affected significantly by $\mathrm{Ca}$ to $\mathrm{Mg}$ substitution at constant basicity and that basicity has a more profound impact on reactivity. The authors also provide insights on the hydration mechanisms and reaction products.

Next to cements in use today, new cements and binders like inorganic polymers ("geopolymers") appear and more innovative uses for slags are also explored. An example demonstrating the above is the work by Labrincha et al. The authors study bauxite residue (red mud) and tionite that results after the processing of titania ores. For bauxite residue, two applications are explored, geopolymers and belite clinker/cement. Tionite was selected to be recycled as ceramic pigment. The results are very promising and although there is still need to refine the processing conditions, this work confirms the potential of certain wastes to replace primary raw materials in the formulation of distinct (some of them high added value) materials. Another work on inorganic polymers is the study by Lancellotti et al., where compositions based on ladle slag, incineration bottom ash and metakaolin were developed. The results show that final dense materials can be synthesised incorporating high amounts of residues (60 and $70 \mathrm{wt} \%$ ) and that the $\mathrm{Ca}$ content as well as the mixture design based on the reactive fraction of each residue are important parameters. The last work on inorganic polymers is the one by Sakkas et al. The authors developed materials for passive fire protection utilising a FeNi slag. Initially, the development of inorganic polymers achieving high compressive strength and low water absorption was described, followed by the development of two fire resistant materials. The fire resistant inorganic polymers were shown to comply with a range of test criteria and also achieved similar or better mechanical strength and thermal conductivity compared with commercially available fire resistant materials. This work demonstrates that other "non-conventional" materials can be employed in the synthesis of inorganic polymers and that more engineered compositions can be developed, targeting specific high added value applications.

The conference itself and the Special Issue herein demonstrate that Slag Valorization is a very active research field. This depth and breadth of ongoing research communicates merely a fraction of the ongoing research and developments in science and technology. It is our belief that Slag Valorization will intensify and gradually become the standard practice, contributing towards near zero-waste processing and closed material loops. 